\title{
Quality Criteria of a Research Output
}

\author{
John KE Mubazi* \\ Kyambogo and Makerere Universities, Uganda \\ *Corresponding author: John KE Mubazi, Kyambogo and Makerere Universities, Kampala, Uganda. \\ To Cite This Article: John KE Mubazi. Quality Criteria of a Research Output. Am J Biomed Sci \& Res. 2019 - 3(3). AJBSR.MS.ID.000674. \\ DOI: 10.34297/AJBSR.2019.03.000674
}

Received: June 08, 2019 | Published: June 12, 2019

\section{Introduction}

An autonomous scholar, whether engaged in teaching, research, or professional service, writes with a clear demonstration of satisfying four criteria: originality, rigour, significance, and coherence. The first three are measures of relative quality while the last demands that the work has a unifying theme. In the subsequent subsections we discuss what each criterion could take into account.

\section{Originality}

Originality means different things in different disciplines. Nonetheless it can mean applying existing stances, methodologies or theories to new data; finding new ways of analysing/theorising existing data; proposing new methods/theories for old problems; reinterpreting existing data or theories and revising old views. It can also mean new knowledge or new theories or new connections with previously unrelated materials [1]. It is argued that the traditional $\mathrm{PhD}$ "privileges the creation of new knowledge over the application, extension, interpretation or questioning of existing knowledge" [2].

It is possible to claim originality in terms of approach, presentation or topic. Original approach includes the use of a new research technique or testing ideas or being the first to try an approach in a particular region or country or disciplinary area. Original topics include subjects which have not previously been researched.

The element of originality in most research is usually small. At Makerere University, "to qualify for a doctorate, there should be strong evidence that the subject is thoroughly understood, with some original thinking" [3].

\section{Rigour}

Different subject disciplines may offer different definitions but rigour is usually linked to robustness of argument and method. It may also refer to methodological advances. However, [4] argue that "when somebody does something for the first time, she may do it brilliantly, but she cannot do it rigorously".
In subject disciplines, economists, for example, like their data hard and methods stiff, and call this rigour. Benchmarks include scientific rigour with regard to design, methods, and analysis. For languages, it could be 'intellectual coherence, methodological precision and analytical power; accuracy and depth of scholarship'. In art, drama, and music, it could be 'the degree of intellectual precision and/or systemic method and/or integrity embodied in the research'.

\section{Significance}

Indicators of significance include showing of achievement of goals, adding consequentially to the field, and opening of additional areas for further exploration.

\section{Coherence}

A provision of a convincing critical narrative about the overall unifying intellectual position of the work may be regarded as coherence. Here "coherence" means "unification" and "cohesion", terms intended to indicate that the work can be seen, and can be shown, to form an integrated whole. On analysis one hopes to find in the work "integration and cohesion" in order to conclude that it demonstrates coherence. On the basis of that vague phrases such as "everything fits together as it should do" can be used to describe the work for it to qualify as being coherent.

The following coherence descriptors are included by [5]:

I. Displaying coherence of structure when conclusions clearly follow from the data.

II. Skillful organisation of a number of different angles.

III. Cogent organisation and expression.

IV. Possessing a definite agenda and an explicit structure.

V. Presenting a sense of the research as a journey, as a structured incremental progress through a process of both argument and discovery. 


\section{It is argued that:}

The key terms here are argument, coherence, discovery, learning, process, progress, organisation and structure. Perhaps it is the final descriptor - of a research project as a completed journey - which best conveys an overall notion of integration and coherence since completed journeys can be said to signify and summarise intellectual processes of planning, travelling (actually or virtually), stopping (addressing, analysing, reflecting on the issues raised in the places visited), overcoming difficulties en route, and arriving at a real or imagined destination [1].

\section{Conclusion}

In conclusion, we also indicate the criteria of publishability that can be identified as criticality, contextualisation, impact, originality, rigour, scale, significance, and topicality. Many of these criteria are subjective, vague and often overlap. For instance, works can be evaluated as original because they are significant, significant because they are original, and paradigm shifting because they are original and significant [6]. In the final analysis what unifies the activities of a scholar is an approach to each task as a novel situation, a voyage of exploration into the partially unknown.

\section{References}

1. Dadley Graham (2009) 'Publish and be Doctor-rated: the PhD by published work". Quality Assurance in Education 17(4): 331-342.

2. Park C (2005) "New Variant PhD: the changing nature of the doctorate in the UK". Journal of Higher Education Policy and Management, 27(2): 189-207.

3. Directorate of Research and Graduate Training (DRGT) 2011 Students Handbook, Kampala, Makerere University, Uganda.

4. Rorty, R (1998) Truth and Progress: Philosophical Papers, Cambridge University Press, UK.

5. Winter R, M Griffiths, K Green (2000) "The Academic Qualities of Practice: what are the criteria for a practice-based PhD?". Studies in Higher Education 25(1): 25-37.

6. Johnson R (2008) "On structuring subjective judgements: originality, significance, and rigour in Research Assessment Exercise (RAE) 2008". Higher Education Quarterly 62(1-2): 120-147. 